\title{
Oral medications for central serous chorioretinopathy: a literature review
}

\author{
William Fusi-Rubiano $\mathbb{1}^{1} \cdot$ Habiba Saedon ${ }^{1} \cdot$ Vijay Patel $^{1} \cdot$ Yit C. Yang ${ }^{1,2}$
}

Received: 28 January 2019 / Revised: 4 June 2019 / Accepted: 27 July 2019 / Published online: 16 September 2019

(c) The Author(s), under exclusive licence to The Royal College of Ophthalmologists 2019

\begin{abstract}
Central serous chorioretinopathy (CSCR) is characterised by acute or chronic neurosensory detachments of the retina, usually in the posterior pole, with or without associated detachments of retinal pigment epithelium. Although the condition often resolves spontaneously, chronic and recurrent cases can lead to significant visual loss in the working population and it is thus increasingly recognised as an important public health issue. The uncertainty regarding the underlying cause of CSCR has led to a wide range of therapies being tried for this condition including photodynamic therapy, laser photocoagulation, anti-VEGF injections and a multitude of oral agents. This article aims to review the current evidence for oral agents that have been used for treatment of CSCR. A systematic literature search was conducted for articles published between 1980 to July 2018. A total of 73 articles were included. These studied the following oral medications: eplerenone, spironolactone, beta blockers, H. pylori agents, omeprazole, rifampicin, methotrexate, aspirin, acetazolamide, mifepristone, melatonin, finasteride, ketoconazole, antioxidants and curcumin phospholipid. Although none of the studies showed robust evidence of efficacy, the mineralocorticoid receptor antagonists, particularly eplerenone, appear to demonstrate the highest quality evidence for use in this condition. The review aims to give the reader an overview of the current available evidence for oral medications used in the treatment of CSCR in order to provide an evidence-based discussion with the patient and guide through possible options for treatment.
\end{abstract}

\section{Introduction}

Central serous chorioretinopathy (CSCR) is characterised by acute or chronic neurosensory detachments of the retina, usually in the posterior pole, with or without associated detachments of retinal pigment epithelium (RPE), of one or both eyes causing patients to experience symptoms of central visual disturbance and blurring [1,2]. These features of CSCR are usually easily visualised on slit-lamp biomicroscopy but the optical coherence tomography (OCT) scan is the main imaging modality used for confirming and monitoring the presence of subretinal fluid (SRF) and/or pigment epithelial detachments (PED) (Fig. 1). CSCR is

William Fusi-Rubiano

William.fusi-rubiano@nhs.net

1 Ophthalmology Department, New Cross Hospital, Wednesfield Road, Wolverhampton WV10 0QP, UK

2 School of Life \& Health Sciences, Aston University, Birmingham B4 7ET, UK usually classified into two types-acute or chronic. In acute cases, SRF resolves within 2-3 months with or without the need for therapeutic intervention [3]. Significant visual loss is uncommon following resolution of acute CSCR, but in recurrent cases of CSCR, there can be significant and permanent reduction of visual acuity associated with atrophy of the RPE and neurosensory layers. CSCR is termed as chronic when it is not self-resolving or has not responded to any therapy and SRF has been persistently present for 3-6 months [3]. The exact duration for terming chronicity is still debated; several studies have used the duration of 3 months to distinguish between acute and chronic cases [46]. These chronic cases are often associated with changes on OCT scan and fundus autofluorescence imaging (Fig. 2) due to the atrophic changes in the neural retina and RPE layer.

CSCR is increasingly recognised as a significant public health issue [7]. Traditionally thought of as occurring in the third and fourth decade, more recent population studies have found the mean age of onset to be between 39 and 45 years and widely ranging from 20 to 65 years [8-10]. A large population study estimated the incidence to be 1 per 100,000 per year with a male to female ratio of 9.9 to 1.7 
Fig. 1 OCT showing SRF and multiple PEDs in patient with CSCR

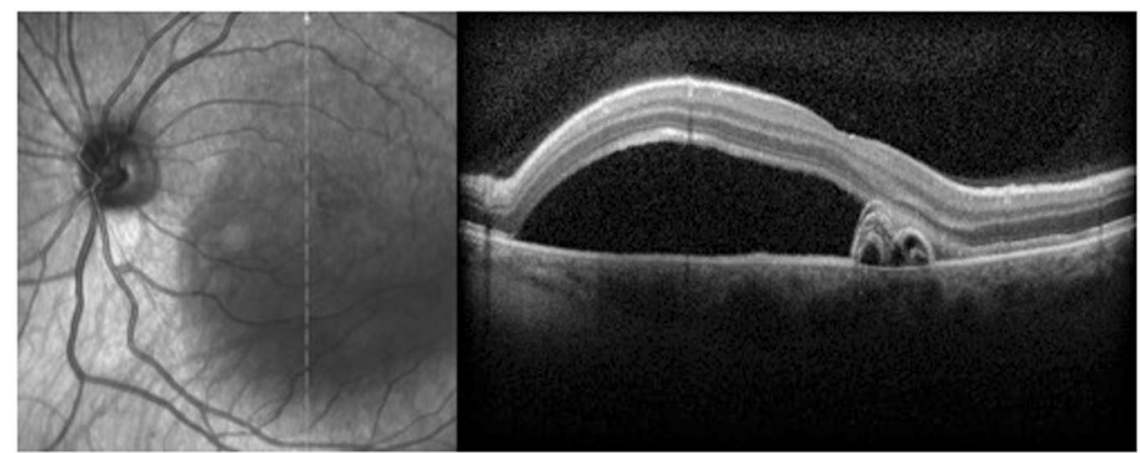

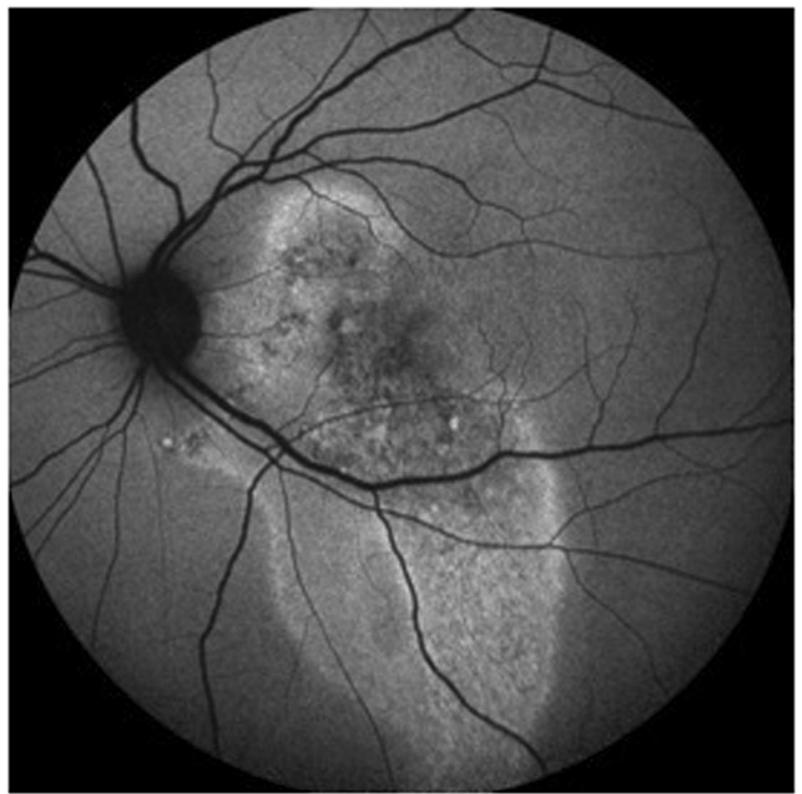

Fig. 2 Fundus autofluorescence image showing RPE changes in chronic CSCR

[8]. Recent genetic studies have identified an association with the Cadherin 5 gene which is linked to corticosteroid metabolism [11]. Both glucocorticoid and mineralocorticoid receptors, thought to be predominantly located in the choroid, have been implicated in the mechanism of CSCR. However, the exact mechanisms are not known [12].

Treatment of CSCR is mainly based on the use of invasive modalities such as photodynamic therapy (PDT), thermal laser photocoagulation and intravitreal anti-vascular growth factor (anti-VEGF) agents. In 2015, these invasive modalities were predominantly evaluated in a Cochrane review but several of the oral agents such as eplerenone, spironolactone, aspirin and melatonin were not included and this meta-analysis concluded that no single treatment provided overwhelming evidence of efficacy [13]. With an ever-increasing variety of proposed oral therapeutic agents, we have conducted a review on all the commonly used oral agents in the treatment of CSCR. This article should provide a valuable resource and evidence base for the retinal clinicians working in the challenging scenario of CSCR who may have to consider the use of non-invasive modalities before embarking on more invasive modalities.

\section{Method for literature search}

We conducted a systematic literature search for articles published between 1980 and July 2018 of Pubmed, Embase, Web of Science, Google Scholar and Medline using search terms: 'central serous chorioretinopathy', 'CSCR', 'CSC', 'CSR', 'central serous retinopathy', 'central serous', 'diffuse retinal pigment epitheliopathy', 'DRPE', 'pathophysiology', 'interventions', 'management', 'treatment'. All articles involving non-interventional management or treatment for CSCR were included.

\section{Results}

A total of 73 articles were identified on eplerenone, spironolactone, beta blockers, H. pylori agents, omeprazole, rifampicin, methotrexate, aspirin, acetazolamide, mifepristone, melatonin, finasteride, ketoconazole, antioxidants and curcumin phospholipid. Table 1 provides a summary of each agent, therapeutic targets and the details of the published studies. In this review, we describe these therapies in order of the number of publications.

\section{Mineralocorticoid receptor antagonists}

Exogenous and endogenous corticosteroid excess has increasingly been found to be associated with CSCR and there is strong evidence that the mineralocorticoid pathway is a predominant pathway in CSCR [14, 15]. Mineralocorticoid receptor antagonists (MRA) in the form of eplerenone and spironolactone have been used as potential treatment options in multiple prospective and retrospective case or comparator studies for CSCR. Van Dijk et al. showed in a cross-sectional study of 13 patients with primary hyperaldosteronism (PA) that retinal abnormalities 


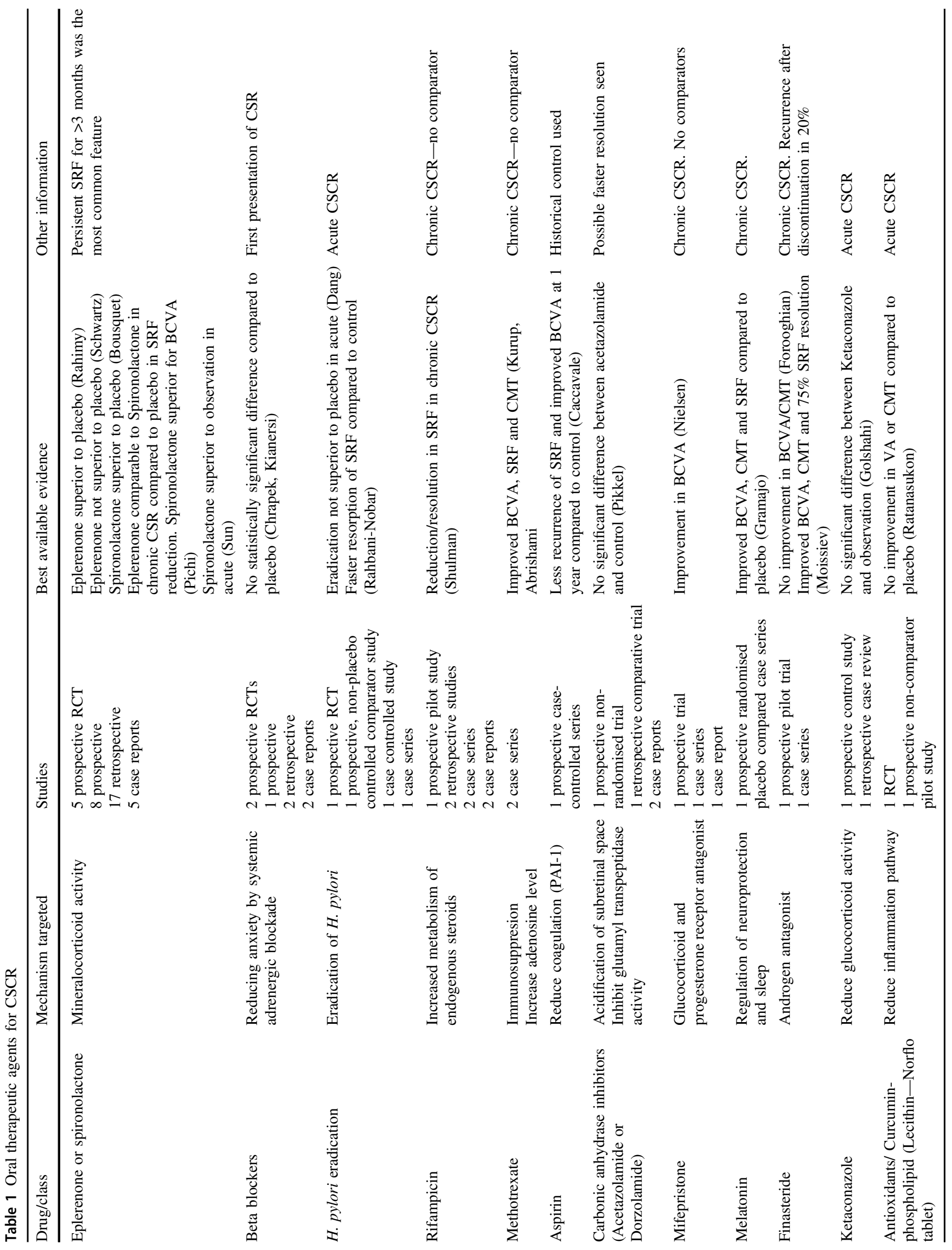


resembling subclinical CSCR are common in patients with PA [15]. In CSCR patients with hypertension of unknown origin, PA should therefore be considered as a differential diagnosis.

Zhao et al. postulated that because glucocorticoids induce and aggravate CSCR, and are known to bind to the mineralocorticoid receptor (MR), CSCR may be correlated with inappropriate MR activation [14]. They aimed to assess the effect of MR activation on rat choroidal vasculature and translate the results to CSCR patients. Intravitreal injection of the glucocorticoid corticosterone in rat eyes, induced choroidal enlargement. Aldosterone, a specific MR activator, produced the same effect, leading to choroid vessel dilation and leakage. They identified that the underlying mechanism of this effect was that aldosterone upregulated the endothelial vasodilatory potassium channel KCa2.3. Its blockade stopped aldosterone-induced thickening. To translate these findings, the authors treated two patients with chronic non-resolving CSCR with oral eplerenone for 5 weeks, and observed rapid retinal reattachment, resolution of choroidal vasodilation and improved visual acuity. This benefit continued 5 months after stopping eplerenone. MR signalling was identified as a pathway controlling choroidal vascular bed relaxation and showed a pathogenic relationship with human CSCR. These results supported the blockade of MR as a treatment strategy for choroidal vasculopathy.

Numerous retrospective and prospective studies have been performed looking at use of both eplerenone and spironolactone in treating CSCR [16-52]. In this section we will only focus on the results of prospective studies and randomised trials for these two agents, but most of the other case reports and studies for chronic CSCR have reported an overall improvement in best corrected visual acuity (BCVA) and an enhanced reduction in/resolution of SRF although recurrence of SRF after cessation has been seen in some studies especially where underlying causative factors persist [34, 47, 51, 52]. A few studies show positive results for use of MRAs in treatment of acute CSCR [26, 41, 42, 47-49, 52]. Although these studies concluded that treatment in acute cases with MRAs can lead to faster resolution, the effect of spontaneous resolution in acute CSCR cases was not accounted for. A full summary of all studies on MRAs can be seen in Table 2.

\section{Eplerenone}

Bousquet et al. in a prospective, uncontrolled noncomparator pilot study looked at 13 patients with nonresolving CSCR, of at least 4 months duration, treated with eplerenone $25 \mathrm{mg} /$ day for 1 week, followed by $50 \mathrm{mg} /$ day for up to 3 months [18]. Results showed significant decrease in CMT and SRF in seven patients at months 1 and 3 in patients on eplerenone compared with baseline and an improvement in BCVA at 3 months. Despite no comparator they argued the non-resolution by 4 months indicated nonprogression and any change was related to eplerenone.

Gergely et al. prospectively looked at eplerenone treatment $(50 \mathrm{mg} /$ day for 3 months) for patients $(n=28)$ with bilateral chronic CSCR, where one eye had SRF and the other none [19]. Results showed a significant decrease in CRT and choroidal thickness in both eyes, although results were smaller in the non-exudative eyes. Decrease in choroidal thickness correlated significantly with resolution of SRF and further points to choroidal activity in CSCR. Improvement in BCVA was only seen in eyes with active SRF at baseline.

A further prospective study by Rajesh et al. looked at predictors of outcome in eplerenone treatment of 11 patients with bilateral chronic CSCR [30]. Of eyes with SRF at baseline $(n=16)$ a significant reduction in SRF was seen in $81.25 \%$ ( $n=13$ eyes). Complete resolution was seen in $37.5 \%$ of eyes $(n=6)$ at month 3 and $62.5 \%(n=10)$ at 6 months. They found that baseline BCVA and 3-month SRF height were significant predictors of final outcome in these patients.

In one of the few prospective, double-blind randomised control trials (RCT) looking at eplerenone in chronic CSCR, Schwartz et al. randomised eyes with chronic CSCR to receive $50 \mathrm{mg} / \mathrm{day}$ or placebo for 3 months [16]. Thirteen eyes were randomised to eplerenone and six to placebo. Both groups showed reduction in SRF at all time points during the study; however, a higher rate of resolution of SRF was found in the placebo group compared to eplerenone $(30.8 \%(n=2)$ vs. $23 \%(n=3)$ respectively). There was no statistically significant difference in BCVA at all time points except month 3 which favoured placebo, leading the authors to conclude that eplerenone was not superior to placebo in treatment of chronic CSCR. Duration of CSCR and number of previous treatments was higher in the treatment group which may play a factor in interpreting the results. Although limited by its small numbers, this is one of the first RCTs to look at this treatment.

In a further prospective, double-blind pilot RCT by Rahimy et al. (ECSELSIOR), 15 patients with chronic CSCR ( $>3$ months) were randomised to either eplerenone (10 patients, 15 eyes) or placebo (5 patients, 6 eyes) in 2:1 ratio [17]. Dose of eplerenone was $25 \mathrm{mg} /$ day for 1 week then $50 \mathrm{mg} /$ day for 2 months. After 2 months, there was a mean reduction in central retinal thickness (CRT) of 82.5 $\mu \mathrm{m}$ and a mean reduction in SRF of 87.5 in the eplerenonetreated eyes, compared to a worsening of SRF and CRT (increase of 36.4 and $35 \mu \mathrm{m}$ respectively) in the placebo group. There was significant improvement in BCVA in the eplerenone treatment group that was not seen in the placebo group. No side effects resulting in cessation of treatment 


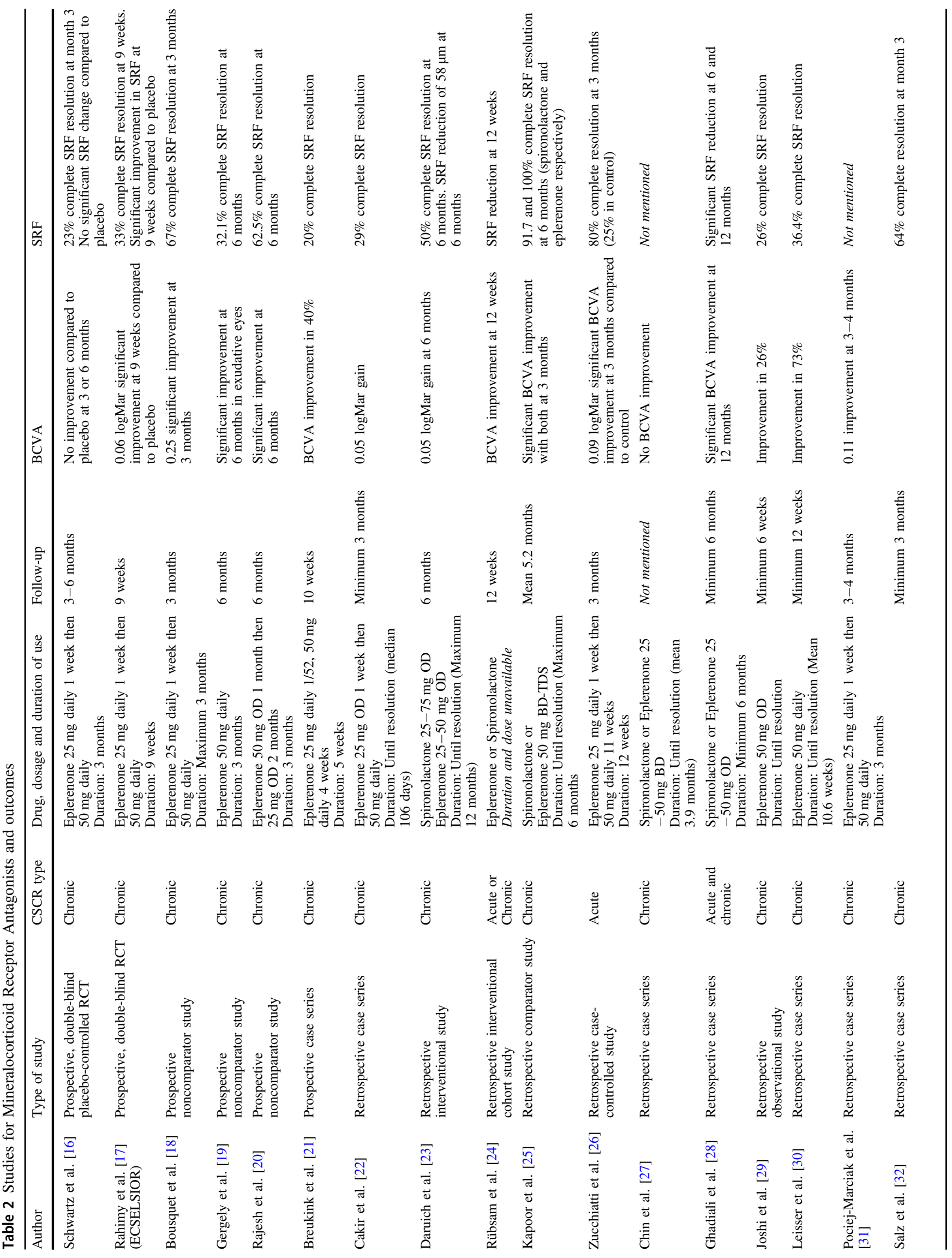




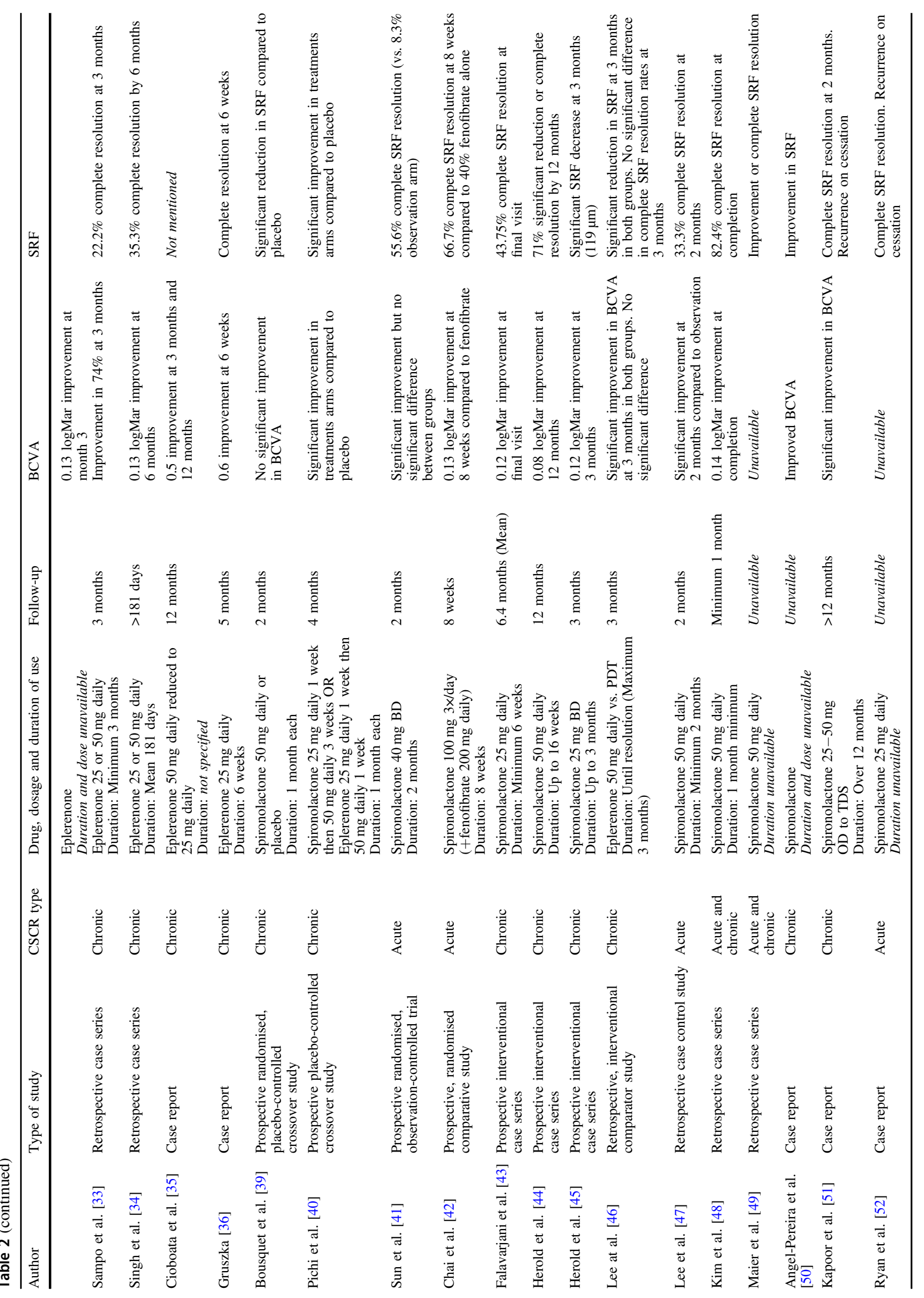


was seen in either group. This valuable RCT study represented a key step forward in the use of eplerenone for CSCR.

There are two RCTs ongoing at present-VICI and SPECTRA. In the first, VICI, a double-masked, placebocontrolled RCT, patients with previously untreated chronic CSCR (>4months) are randomised in a 1:1 ratio to either receive eplerenone $(25 \mathrm{mg}$ daily for 1 week, then $50 \mathrm{mg}$ daily) with usual care or placebo with usual care for up to 12 months [37]. Main outcome is BCVA at 12 months with secondary outcomes of resolution of SRF, development of macular atrophy, subfoveal choroidal thickness, changes in low luminance VA, healthy related quality of life (QOL) and safety. The second, SPECTRA, is the first RCT to directly compare PDT and eplerenone in chronic CSCR [38]. Patients are randomised to either half-dose PDT or eplerenone $25 \mathrm{mg}$ daily for 1 week then $50 \mathrm{mg}$ daily for 11 weeks with follow-up up to 2 years. Main outcome is resolution of SRF at 3 months with secondary outcomes macular sensitivity, BCVA change, vision-related QOL, number of crossover treatments needed in each arm, long term outcomes after successful and unsuccessful treatment, and safety.

Treatment with eplerenone has the most published evidence to support its use of all oral therapies in treating CSCR. Although the most recent RCTs showed opposing conclusions for the benefit of eplerenone, the numerous prospective and retrospective studies have shown some support of its use in chronic CSCR. Further large RCTs are needed for a more solid evidence base.

\section{Spironolactone}

Spironolactone has a similar mechanism to eplerenone and has also been extensively investigated in CSCR.

Bousquet et al. performed a prospective, randomised, placebo-controlled crossover study to evaluate the effect of spironolactone for non-resolving CSCR [39]. Sixteen eyes of 16 patients with persistent SRF for at least 3 months were randomised to receive either spironolactone $50 \mathrm{mg}$ or placebo once a day for 30 days. This was followed by a washout period of 1 week and then crossed over to either placebo or spironolactone for another 30 days. The mean duration of CSCR before enrolment in study eyes was $10 \pm$ 16.9 months. Crossover analysis showed a statistically significant reduction in SRF in spironolactone-treated eyes as compared with the same eyes under placebo and a significant reduction in subfoveal choroidal thickness up to day 30 in treated eyes compared to placebo. There was no significant change in BCVA. No complications related to treatment were reported.

Another prospective, placebo-controlled trial by Pichi et al. compared treatment with eplerenone to spironolactone in patients with chronic CSCR [40]. Three treatment arms were compared: Group $1(n=20)$ received spironolactone $25 \mathrm{mg} /$ day for 1 week increasing to $50 \mathrm{mg} /$ day for 3 weeks. After 4 weeks, they were then switched to eplerenone $50 \mathrm{mg}$ for 4 weeks. Group $2(n=20)$ received eplerenone $25 \mathrm{mg} /$ day for 1 week increasing to $50 \mathrm{mg} /$ day for 3 weeks, after which, they were switched to spironolactone $50 \mathrm{mg} /$ day for 4 weeks. Group 3 was treated with one tablet of placebo for 1 week increasing to two tablets for 3 weeks, after which, they were switched to receive spironolactone $50 \mathrm{mg} /$ day for 4 weeks. In all three arms, treatment was stopped after 2 months and patients observed for a further 2 months. BCVA significantly improved in group 1 during the first 4 weeks (spironolactone) and in group 2 from the second 4 weeks (switch to spironolactone). Groups 1 and 2 had significant but equivocal reduction in SRF after 1 month of treatment. At month 4, BCVA and SRF were significantly improved in groups 1 and 2, but there was no significant improvement in group 3. Authors conclude that spironolactone was comparable to eplerenone in improving SRF, but that it was statistically superior to eplerenone at improving BCVA. Both were superior to placebo in reducing SRF and improving BCVA.

There has been only one prospective, randomised observation-controlled trial looking at acute CSCR. Sun et al. looked at treatment of acute CSCR with spironolactone $40 \mathrm{mg}$ BD for 2 months compared to observation alone [41]. Complete resolution of SRF occurred in $55.6 \%$ (10/18 eyes) in the spironolactone treatment arm and $8.3 \%$ ( $1 / 12$ eyes) in the observation arm. Reduction in CRT was seen in both groups; however, the reduction compared to baseline was only significant in the spironolactone group (75 $\mu \mathrm{m}$ reduction). Despite this, there was no significant difference between the two groups for improvement in BCVA and SRF at 2 months with both groups showing improved vision and reduction in SRF. Although the authors concluded spironolactone showed benefit in acute CSCR, the spontaneous resolution seen in the observation group is an important factor to consider in the short-term management of patients with acute CSCR.

Studies on spironolactone also showed encouraging results although most of the available evidence is from small and retrospective studies. Further larger prospective randomised trials are still needed to better elucidate the role of spironolactone in the management of CSCR.

Despite good clinical outcomes, systemic side effects, even at low doses, may occur with the use of MRAs $[23,25]$. The main side effects are hyperkalemia, hypotension, hypertriglyceridemia, hyponatremia, mastodynia, abnormal vaginal bleeding and gynaecomastia $[53,54]$. The latter side effects (mastodynia, vaginal bleeding and gynaecomastia) appear to be less with eplerenone due to its selectivity for the aldosterone receptor [54, 55]. Although 
these have been shown to reverse on cessation, patients may require ongoing blood tests and observation. The VICI trial protocol suggests it is not suitable for patients with hepatic impairment or an eGFR $<30 \mathrm{ml} / \mathrm{min}$ per $1.73 \mathrm{~m}^{2}$ as well assessing potassium levels at each visit [37]. If serum potassium exceeds $5 \mathrm{mmol} / \mathrm{l}$ at any time point the treatment should be stopped [37]. Although the protocol relates to eplerenone alone, it seems a reasonable cut off for patients in the real-world setting receiving eplerenone or spironolactone.

\section{Beta blockers}

Anti-adrenergics like beta blockers are used in a variety of diseases including hypertension and anxiety [55]. The longobserved association of CSCR with stress and type-A personality has led to the postulated role of adrenergic blockade as a possible therapeutic option for CSCR [56].

Chrapek et al. in a prospective, double-blind study compared metipranolol $10 \mathrm{mg}$ b.d $(n=23)$ to placebo $(n=$ 25) in 48 patients presenting with a first episode of CSCR [57]. There was no significant difference in baseline duration of CSCR or mean BCVA. Sixteen patients achieved full resolution of SRF within 4 weeks with metipranolol, compared with 21 patients in the placebo group, although this was not statistically significant. Browning in a study looking at the use of nadolol in treatment of CSCR also showed no definitive effect [58]. In a further double-blind, RCT comparing propranolol $20 \mathrm{mg}$ b.d. to control in CSCR, Kianersi and Fesharaki found significant reduction in duration of CSCR with propranolol (62 \pm 29 days vs. $89 \pm$ 44 days); however, there was no statistically significant difference between final mean BCVA in the two groups [59]. Shorter duration of CSCR with propranolol may have a role in improved patient visual quality and contrast sensitivity; however, this was not measured in the study.

Tatham and Macfarlane presented case reports of two patients with non-resolving CSCR treated with propranolol $40 \mathrm{mg}$ b.d. [60]. BCVA and CMT improved in both patients yet spontaneous resolution is still plausible. Fabianova et al. also found positive findings in first attacks of CSCR treated with trimepranolol $10 \mathrm{mg}$ b.d. and metoprolol $50 \mathrm{mg}$ b.d., with remission occurring in 4 weeks in both sets [61]. Despite this positive finding, the lack of a control group meant that spontaneous resolution might have occurred anyway.

In summary, beta blockers may have some effect on CSCR; however, the strength of evidence is not sufficiently supportive for their use in practice.

\section{Helicobacter pylori eradication}

There is increasing evidence that Helicobacter pylori (H. pylori), a gram-negative bacterium, is an important pathogen in peptic ulcers, gastric cancer and MALT lymphoma, as well as extra-gastric disorders such as idiopathic thrombocytopenic purpura, iron deficiency anaemia, cardiovascular disease, atherosclerosis and more recently CSCR [62, 63]. The association between H. Pylori and CSCR has been documented, but is poorly understood [64].

H. pylori infections are prevalent in over $50 \%$ of adult humans globally [65]. Numerous studies have documented an association of CSCR with H. pylori infection with a higher prevalence in patients with CSCR than in controls, suggesting that the infection may influence pathological processes inherent in CSCR [66-73].

The clinical outcome of $H$. pylori infection is determined by interaction between the bacterium and the host, with the pathophysiology of extra-gastric manifestations of $H$. pylori postulated to occur through mechanisms including molecular mimicry, release of inflammatory mediators and abnormal production of vasoactive substances [65, 74]. This theory suggests that the gastric infection induces an immune response to $H$. pylori antigens (anti-CagA antibodies), which propagates an autoimmune response to homologous host proteins in satellite tissues, such as the endothelium of the choroidal vasculature and the RPE of the retina [70]. The infection may also alter vascular function by increasing endothelin 1, nitric oxide synthase and nitric oxide, potentially contributing to microangiopathies such as CSCR $[75,76]$.

Various small studies have been published on H. pylori eradication therapy (commonly a combination of metronidazole or clarithromycin + amoxicillin and omeprazole) reporting improving SRF, faster resolution time compared to controls, and improving visual acuity $[66,69,71,77,78]$.

In a randomised, placebo-controlled trial by Dang et al., patients with acute CSCR, confirmed to have H. pylori, were randomised to receive either $H$. pylori eradication therapy or placebo [79]. Group $1(n=32)$ received clarithromycin $500 \mathrm{mg}+$ amoxicillin $1 \mathrm{~g}+$ omeprazole $20 \mathrm{mg}$ for 2 weeks and group $2(n=32)$ received placebo for 2 weeks. Patients were followed up at 2, 4, 8 and 12 weeks. Authors found that there was no significant difference in improvement in BCVA or resolution of SRF between the two groups, but that central retinal sensitivity in acute idiopathic CSCR patients improved in the treatment arm. The improvement in retinal sensitivity was probably via a direct effect of proton pump inhibition in the retinal photoreceptor transduction process. In a further non-placebocontrolled prospective comparator study, Zavoloka et al. looked at 93 patients with acute CSCR comparing three groups [80]. Patients were divided into: Group $1(n=33)$ H. Pylori + ve patients who received eradication therapy; Group $2(n=29)$ who received no eradication treatment; Group $3(n=31)$ who were H. pylori - ve. Overall there was a mean decrease in duration time at 3 months $(p=0.04)$ and 
recurrence of $45.9 \%$. At 2-year follow-up there was also an improvement in VA as well as reduction in scotoma and metamorphopsia frequency.

Despite the association with CSCR, there does not appear to be a good enough evidence base to support the routine use of $H$. pylori eradication therapies for treatment of CSCR.

\section{Rifampicin}

Rifampicin is used in the treatment of tuberculosis (TB) and has recently been reported to have anti-oxidative, antiapoptotic, and anti-angiogenic effects [81]. Its primary mechanism of action is inhibition of DNA-dependent RNA polymerase, blocking the transcription of RNA [82]. It is a cytochrome P450, 3A4 inducer which catalyses many reactions involved in drug metabolism and synthesis of cholesterol, steroids and other lipids [83, 84]. Thus, it was postulated that induction of cytochrome P450 3A4 may increase metabolism of endogenous steroids leading to improvement of CSCR manifestations. Rifampicin has numerous common and more serious side effects that include hepatitis, haematological abnormalities, renal failure and anaphylaxis $[85,86]$. Therefore, baseline measurement of liver enzymes, bilirubin, serum creatinine, complete blood count and platelet count is suggested prior to initiation [86].

The first case reports of rifampicin in CSCR reported an association with improvement in CSCR and recurrence after cessation of rifampicin in patients with CSCR being treated for TB [87, 88]. Since then further cases have reported resolution or reduction in SRF of chronic CSCR and improved visual acuity in those treated with rifampicin $[89,90]$.

A prospective, pilot study by Shulman et al. investigated patients with chronic CSCR who were treated with oral rifampicin $300 \mathrm{mg}$ twice per day for 3 months and had 6 months of follow-up [91]. This dose was used because Mårde Arrhén et al. demonstrated that an induction of cytochrome P450 3A4 occurs only with a daily dose of $500 \mathrm{mg}$ rifampicin, but not with lower doses [92]. Fourteen eyes of 12 patients were included in the pilot study. Mean duration of SRF prior to study entry was 28.4 months. Forty-two per cent of eyes were treated previously for CSCR with thermal laser, PDT, or intravitreal bevacizumab. There was a non-significant improvement in BCVA at month 3. SRF was reduced in nine eyes $(64 \%)$ and completely resolved in six eyes $(42.8 \%)$ at month 3 , and four out of these six eyes remained fluid free at month 6. Two patients stopped the treatment after 2 months due to adverse events. A further observational study by Khan et al., with CSCR treated with rifampicin $300 \mathrm{mg}$ once daily for 3 months, found an improvement in
BCVA and CMT at all time points up to 4 months [93]. Thirty-eight eyes of 31 patients were included. Mean CMT reduction at month 4 of $249.71 \mu \mathrm{m}$ and BCVA improvement was 0.49 . This was a non-comparator study and the majority of patients were acute cases $(74.2 \%)$ compared to Schulman. There was long-term follow-up data for this study. In a smaller retrospective study, Venkatesh et al. looked at patients with chronic CSCR treated with rifampicin $600 \mathrm{mg}$ once daily for a maximum of 3 months and mean follow-up of 10 months [94]. Full SRF resolution was seen in $44.4 \%(n=4)$ and mean VA improved in these patients. No recurrence occurred in these eyes. Of those without resolution, only two eyes had VA improvement. Two patients developed side effectsheadache $(n=1)$, diarrhoea $(n=1)$-during the study and treatment was stopped after 1 month. Lack of comparator, small numbers and the retrospective nature of the study limited its conclusions.

A case of hepatotoxicity, secondary to off-label rifampicin therapy, for the treatment of chronic CSCR, was reported by Nelson et al. [95]. Three weeks after the initiation of rifampicin therapy, fatigue, nausea, and malaise, associated with elevated liver enzyme elevations, were noted. Symptoms resolved and liver enzymes normalised after discontinuing rifampicin. This may limit the use of rifampicin in some patients.

Given the variable results from only one small prospective study and the risk of systemic side effects, our current knowledge does not support routine use of rifampicin in CSCR.

\section{Methotrexate}

Methotrexate (MTX) is a commonly used anti-metabolic agent for the treatment of systemic and ophthalmic inflammatory disorders such as rheumatoid arthritis and uveitis and is relatively inexpensive [96]. MTX has various effects on the immune system. Although mechanism of action was initially thought to be related to immune suppression, other mechanisms of action have been identified including increasing adenosine levels, anti-angiogenic effects and interaction with progesterone receptors in animal models. Many of these effects seem to be dosedependent [97-99].

Kurup et al. performed a retrospective review of nine eyes of nine patients treated with oral MTX as treatment for chronic CSCR in three different centres [100]. Mean duration of CSCR was 28 months. Mean starting dose of MTX was $7.04 \mathrm{mg}$ (range $5-10 \mathrm{mg}$ ), and mean final dose was $7.27 \mathrm{mg}$ (range $5-10 \mathrm{mg}$ ). The mean duration of treatment was 89 days. There were statistically significant improvements in mean BCVA, CMT and total macular volume at 8 weeks. Eighty-three per cent of the patients achieved total 
resolution of SRF. No MTX-associated toxicity was evident.

Similar results were presented in another study by Abrishami et al. that included 23 eyes of 23 consecutive patients presenting with chronic symptomatic CSCR with SRF persisting $>3$ months [101]. All patients were treated with $7.5 \mathrm{mg} /$ week of oral MTX for 12 weeks. The BCVA, CMT, SRF, and total macular volume showed statistically significant improvement. Thirteen (62\%) eyes achieved complete resolution of SRF. No MTX-associated toxicity was detected.

MTX is a potentially attractive option for the treatment of CSCR and it may have a role in the treatment of chronic CSCR as evidenced by these results. However, these were uncontrolled studies and therefore randomised, controlled clinical trials are warranted to further investigate the effects of methotrexate in these patients.

\section{Aspirin}

In some cases of CSCR, increased levels of plasminogen activator inhibitor have been demonstrated compared with controls [102, 103]. Consequently, it has been suggested that hypercoagulability may play a role in CSCR pathogenesis [104]. A small case series from 1978 of four patients with CSCR treated with ibuprofen suggested some benefit, although, this has not been followed by subsequent studies since that time [105]. Others have also found elevated PAI-1 in patients with CSCR [102, 103]. Aspirin has anti-aggregant effects and is effective in reducing serum levels of PAI-1 [106].

Given the evidence of a role for PAI-1 in the pathophysiology of CSCR, a pilot study was performed by Caccavale et al. [107]. All patients were prescribed aspirin $100 \mathrm{mg}$ once daily for the first month and on alternate days for the following 5 months. The prospective case series undergoing treatment (Group A: 109 patients, 113 eyes) was compared with a historical control group consisting of patients with either classic or multifocal CSCR (Group B: 89 patients, 95 eyes). Primary endpoints were BCVA and number of recurrences. BCVA improved in both groups at months 1 and 3; however, BCVA improvement at 1 year was better in group A. Recurrence was seen in $14 \%$ of group A and $43 \%$ in group B. $6.5 \%$ experienced 1-3 relapses of disease compared to $23 \%$ in group B and $7.5 \%$ showed a persistence of SRF compared to $20 \%$ in group B. None of the patients manifested adverse reactions to aspirin. A gastrointestinal risk exists but appears to be minimal (3\%) with low dosages [108].

The results of this study demonstrated possible efficacy of lower-dose aspirin in the treatment of CSCR, with improvement in BCVA and better recurrence rate profile than control. The study is limited by use of an historic group as a control. As expected, due to the self-limiting nature of CSCR, a spontaneous improvement of BCVA in the untreated group in the period between 1 and 3 months was observed. There appears to be promise in the use of aspirin; however, studies are extremely limited and further trials are required.

\section{Carbonic anhydrase inhibitors}

Acetazolamide is a carbonic anhydrase inhibitor used to treat glaucoma and raised idiopathic intracranial hypertension. It has been reported to be effective in decreasing macular oedema associated with various intraocular pathologies and surgery [109, 110]. It has been used offlabel to treat CSCR on the basis that inhibition of carbonic anhydrase IV in the RPE could promote resorption of SRF and induce the restoration of normal polarisation in RPE as well as the potential to inhibit glutamyl transpeptidase activity in ocular tissues [109, 111-113]. This inhibition aids cellular adhesion, neutrophil chemotaxis, and degradation through elevation of leukotriene D4 concentration [114]. This mechanism may favourably influence CSCRrelated macular oedema and may contribute to its resolution. The use of carbonic anhydrase inhibitors in the treatment of CSCR has been suggested but only investigated in one clinical trial [24, 109, 114-117].

In a prospective, non-randomised, comparative trial by Pikkel et al., 15 patients were treated with acetazolamide and compared with 7 untreated (control) CSCR patients [118]. At least 24 months of follow-up was completed. They found that the time for subjective and objective clinical resolution was shortened, but there was no effect on either final visual acuity or recurrence rate of the disease. Seventy-three per cent of the patients in the study group reported side effects from the medication, including paraesthesia, nervousness, and gastric upset. The authors suggested that patients with CSCR, who require accelerated resolution and subjective improvement in vision, may be considered candidates for treatment with acetazolamide.

A retrospective comparison by Rübsam et al. looked at 93 eyes with acute and chronic CSCR treated with observation $(n=8)$, acetazolamide $(n=37)$ or MRAs $(n=20)$ [24]. There was an overall improvement in SRF in all groups which was significant for the acetazolamide and MRA groups. They also found that non-responders to acetazolamide, who were switched to MRAs $(n=27)$, showed a significant reduction in SRF; however, this was not seen for those switched from MRAs to acetazolamide.

Despite the theoretical rationale, strong evidence to support the use of acetazolamide in CSCR is currently lacking. Side effects are common and may limit its use. Further trials would be required to demonstrate efficacy of acetazolamide in this condition. 


\section{Mifepristone}

Mifepristone (RU-486) is a high-affinity, glucocorticoid and progesterone receptor antagonist [119]. It is used to end an early pregnancy for women who have been pregnant for 49 days (seven weeks) or less [120]. Nielsen et al. reported a case of successful treatment of CSCR with oral mifepristone $[121,122]$. The same group later reported on 16 patients with chronic CSCR in an uncontrolled study [123]. Oral mifepristone $200 \mathrm{mg}$ was administered daily for up to 12 weeks. Seven patients gained $\geqslant 5$ letters of vision, and seven patients had improved OCT findings. There were no serious adverse events. This led to the conclusion that oral mifepristone has a beneficial effect in some CSCR cases. However, this was an uncontrolled study and there have been no further studies published on the use of mifepristone in CSCR.

The results of the first RCT for mifepristone (STOMPCSC) were recently presented by Goldberg and Heier [124]. In this randomised, double-masked placebo-controlled study 30 patients with chronic or recurrent CSCR were randomised to receive either mifepristone $300 \mathrm{mg}$ daily, mifepristone $900 \mathrm{mg}$ daily or placebo for 4 weeks. After treatment, patients were observed for a further 4 weeks. In both treatment groups, there was a statistically significant reduction in CRT of $82 \mu \mathrm{m}(p<0.05)$ and improvement in BCVA of $3.6 \mathrm{~L}(\mathrm{p}<0.05)$. This compared to a nonstatistically significant reduction in CRT $(47 \mu \mathrm{m}, p=0.45)$ or BCVA $(0.7 \mathrm{~L}, p=0.64)$ in the placebo group. There was no statistically significant difference between outcomes for the two treatment groups. There were no significant side effects. This is the first RCT for mifepristone and shows promising results and we await full results of this study. Despite this, further larger studies are still required to determine potential benefits of mifepristone.

\section{Melatonin}

Melatonin is involved in physiological regulation and participates in the normal regulation of sleep, as well as potentially playing a role in neuroprotection $[125,126]$. Gramajo et al. in a prospective, randomised, comparative case series of 13 patients compared melatonin $3 \mathrm{mg}$ three times per day $(n=8)$ with placebo $(n=5)$ in patients with chronic CSCR [127]. Previous treatments included: anti-VEGF $(n=6)$, laser $(n=1)$ non-steroidal anti-inflammatories $(n=1)$ or no treatment. Patients with prior laser or anti-VEGF in the last 3 months were excluded.

At 1 month, BCVA improved in $87.5 \%$ of melatonintreated patients from baseline of 0.29 to 0.12 , and all patients had reduction in CMT, with three having total resolution. No change in CMT or SRF was seen in the placebo group and worsening BCVA 0.28 to 0.36 was seen.
One patient in the melatonin arm had subsequent recurrence at 1 year follow-up. No unexpected adverse effects were experienced, although two patients reported drowsiness for the initial $24-48 \mathrm{~h}$ after initiation of treatment.

This is the first study to look at melatonin in CSCR and, although promising, further studies are needed to ascertain whether this may be a viable treatment for CSCR.

\section{Finasteride}

Finasteride is 5 alpha-reductase, an inhibitor of dihydroxytestosterone often used in the treatment of benign prostatic hypertophy and androgenic alopecia [128-130]. As well as glucocorticoids, androgens have been proposed in the pathogenesis of CSCR, and therefore antagonists may theoretically be an aid to treatment.

Forooghian et al. in a prospective, pilot study treated patients with chronic CSCR with finasteride $5 \mathrm{mg}$ o.d. for 3 months [131]. Five eyes of five patients were included. There was no change in BCVA with treatment. Reduction in CMT and SRF was seen at 3 months, although this was not statistically significant. No patients had full resolution.

Increase in SRF after discontinuation was seen in four patients. One patient reported loss of libido that resolved after discontinuation of the drug. No statistically significant benefit for finasteride has been shown from this study.

This is in contrast to the results of Moisseiev et al. looking at the safety and efficacy of finasteride $5 \mathrm{mg}$ o.d. in 29 eyes with chronic CSCR in a retrospective case series [132]. A minimum of 3 to maximum 6 months was given. Six had previous treatments: 3 PDT, 2 anti-VEGF, 1 both. There was a significant improvement in mean VA and CMT improving from 0.29 at baseline to 0.23 , and from 354 to $247 \mu \mathrm{m}$ at final visit. SRF resolution was seen in $33.3 \%$ at 1 month, $52.7 \%$ at 3 months and $75.9 \%$ at final visit. Recurrence of SRF was seen in six eyes (20.4\%) after discontinuation and seven (24.1\%) underwent further treatment with PDT after finasteride. No adverse effects were seen.

Finasteride may play a role in treatment of CSCR; however, the evidence is mixed. As a relatively inexpensive drug that is well tolerated, finasteride is a potentially economically viable avenue to pursue. Further prospective, control trials are needed to expand the data available.

\section{Ketoconazole}

Ketoconazole is a synthetic imidazole, which is used for its anti-fungal properties, but also has anti-glucocorticoid effect [133, 134].

Meyerle et al. looked at 5 patients with CSCR treated with ketoconazole $600 \mathrm{mg}$ od for 4 weeks in a retrospective case review [135]. Mean BCVA and OCT findings showed 
no change from baseline, at 4 weeks or 8 weeks, despite measured endogenous cortisol being lower at week 4 .

Golshahi et al. showed similar findings in a non-randomised, control study comparing ketoconazole $200 \mathrm{mg}$ /day to control in patients with CSCR for 4 weeks [136]. Mean BCVA and OCT changes improved in both arms but there was no statistically significant difference between groups.

Despite the theoretical treatment effect, there has so far been no evidence to suggest the use of ketoconazole in CSCR.

\section{Antioxidants and curcum-phospholipids}

As discussed, inflammation and oxidative stress have been hypothesised as a causative pathway in CSCR. In a randomised, placebo-controlled trial by Ratanasukon et al., patients with acute CSCR were assigned to receive highdose antioxidants or placebo for 3 months or until resolution of SRF [137]. There was found to be no statistically significant difference between the groups in reduction of CMT or improvement in BCVA; however, there was a reduction in additional treatment needed at the end of 3 months in the antioxidant arm.

Further studies by Mazzolani et al. looked at the effect of curcumin-phospholipid (lecithin) formulation (Norflo), another antioxidant, in 18 eyes of 12 patients with acute and chronic CSCR $[138,139]$. There was reduction in neuroretinal thickness at 6 months and 95\% showed reduction at 12 months. Mean BCVA improved at 6 months and $61 \%$ showed statistically significant improvement at 12 months with no patients reducing VA. Lack of comparison in this study allows the possibility of spontaneous resolution to occur; thus, the results must be interpreted with caution.

The evidence does not suggest the use of antioxidants for treatment of acute CSCR; however, it may play a role in reduction of treatment needed in chronic cases. However, further comparative studies would be needed to look at its use in both acute and more chronic cases.

\section{Conclusions}

This review has presented an overview of the scientific literature available for the evidence of the use of oral medications for the treatment of CSCR. Although none of the studies presented have provided robust evidence of efficacy of the medications presented, the MRAs, especially eplerenone, appear to have the best evidence for use in this condition, and may be suitable as a first line, non-invasive treatment to be tried in patients who decline or are unsuitable for other more invasive treatment modalities such as laser photocoagulation, PDT or intravitreal anti-VEGF injections.

\section{Compliance with ethical standards}

Conflict of interest The authors declare that they have no conflict of interest.

Publisher's note Springer Nature remains neutral with regard to jurisdictional claims in published maps and institutional affiliations.

\section{References}

1. Gass JDM. Stereoscopic atlas of macular diseases. St Louis, MO: Mosby; 1997.

2. Gass JDM. Pathogenesis of disciform detachment of the neuroepithelium. Am J Ophthalmol. 1967;63:587.

3. Wong KH, Lau KP, Chhablani J, Tao Y, Li Q, Wong IY. Central serous chorioretinopathy: what we have learnt so far. Acta Ophthalmol (Copenh). 2016;94:321-5.

4. Chan WM, Lai TY, Lai RY, Tang EW, Liu DT, Lam DS. Safety enhanced photodynamic therapy for chronic central serous chorioretinopathy: one-year results of a prospective study. Retina. 2008;28:85-93.

5. Reibaldi M, Cardascia N, Longo A, Furino C, Avitabile T, Faro S, et al. Standard-fluence versus low-fluence photodynamic therapy in chronic central serous chorioretinopathy: a nonrandomized clinical trial. Am J Ophthalmol. 2010;149:307-15.e2.

6. Shin JY, Woo SJ, Yu HG, Park KH. Comparison of efficacy and safety between half-fluence and full-fluence photodynamic therapy for chronic central serous chorioretinopathy. Retina. 2011;31:119-26.

7. Liew G, Quin G, Gillies M, Fraser-Bell S. Central serous chorioretinopathy: a review of epidemiology and pathophysiology. Clin Exp Ophthalmol. 2013;41:201-14.

8. Kitzmann AS, Pulido JS, Diehl NN, Hodge DO, Burke JP. The incidence of central serous chorioretinopathy in Olmsted County, Minnesota, 1980-2002. Ophthalmology. 2008;115: $169-73$.

9. Tsai DC, Chen SJ, Huang CC, Chou P, Chung CM, Huang PH, et al. Epidemiology of idiopathic central serous chorioretinopathy in Taiwan, 2001-2006: a population-based study. PLoS ONE. 2013;8:e66858.

10. Haimovici R, Koh S, Gagnon DR, Lehrfeld T, Wellik S. Risk factors for central serous chorioretinopathy: a case-control study. Ophthalmology. 2004;111:244-9.

11. Schubert C, Pryds A, Zeng S, Xie Y, Freund KB, Spaide RF, et al. Cadherin 5 is regulated by corticosteroids and associated with central serous chorioretinopathy. Hum Mutat. 2014;35:859-67.

12. Bouzas EA, Karadimas P, Pournaras CJ. Central serous chorioretinopathy and glucocorticoids. Surv Ophthalmol. 2002;47: 431-48.

13. Salehi M, Wenick AS, Law HA, Evans JR, Gehlbach P. Interventions for central serous chorioretinopathy: a network metaanalysis. Cochrane Database Syst Rev. 2015;12:CD011841.

14. Zhao M, Célérier I, Bousquet E, Jeanny JC, Jonet L, Savoldelli $\mathrm{M}$, et al. Mineralocorticoid receptor is involved in rat and human ocular chorioretinopathy. J Clin Invest. 2012;122:2672-9.

15. Van Dijk EH, Nijhoff MF, de Jong EK, Meijer OC, de Vries AP, Boon CJ. Central serous chorioretinopathy in primary hyperaldosteronism. Graefes Arch Clin Exp Ophthalmol. 2016;254: 2033-42.

16. Schwartz R, Habot-Wilner Z, Martinez MR, Nutman A, Goldenberg D, Cohen $S$, et al. Eplerenone for chronic central serous chorioretinopathy-a randomized controlled prospective study. Acta Ophthalmol (Copenh). 2017;95:e610-18. 
17. Rahimy E, Pitcher JD 3rd, Hsu J, Adam MK, Shahlaee A, Samara WA, et al. A randomized double-blind placebo-control pilot study of eplerenone for the treatment of central serous chorioretinopathy (ECSELSIOR). Retina. 2018;38:962-69.

18. Bousquet E, Beydoun T, Zhao M, Hassan L, Offret O, BeharCohen F. Mineralocorticoid receptor antagonism in the treatment of chronic central serous chorioretinopathy: a pilot study. Retina. 2013;33:2096-102.

19. Gergely R, Kovács I, Schneider M, Resch M, Papp A, Récsán Z, et al. Mineralocorticoid receptor antagonist treatment in bilateral chronic central serous chorioretinopathy: a comparative study of exudative and nonexudative fellow eyes. Retina. 2017;37:1084-91.

20. Rajesh B, Agrawal H, Peguda HK, Chhablani J. Predictors of outcome during eplerenone therapy in chronic central serous chorioretinopathy: a prospective, open-label pilot clinical study. Ophthalmic Surg, Lasers Imaging Retin. 2018;49:479-86.

21. Breukink MB, den Hollander AI, Keunen JEE, Boon CJF, Hoyng CB. The use of eplerenone in therapy-resistant chronic central serous chorioretinopathy. Acta Ophthalmol. 2014;92: e488-90.

22. Cakir B, Fischer F, Ehlken C, Bühler A, Stahl A, Schlunck G, et al. Clinical experience with eplerenone to treat chronic central serous chorioretinopathy. Graefes Arch Clin Exp Ophthalmol. 2016;254:2151-7.

23. Daruich A, Matet A, Dirani A, Gallice M, Nicholson L, Sivaprasad S. et al. Oral mineralocorticoid-receptor antagonists: reallife experience in clinical subtypes of nonresolving central serous chorioretinopathy with chronic epitheliopathy. Transl Vis Sci Technol. 2016;5:2.

24. Rübsam A, Thieme CE, Schlomberg J, Winterhalter S, Müller B, Joussen AM, et al. Therapy rationale for mineralocorticoidreceptor antagonists, acetazolamide and a switch of therapy in nonresponders in central serous chorioretinopathy. J Ocul Pharm Ther. 2017;33:141-8.

25. Kapoor KG, Wagner AL. Mineralocorticoid antagonists in the treatment of central serous chorioretinopathy: a comparative analysis. Ophthalmic Res. 2016;56:17-22.

26. Zucchiatti I, Sacconi R, Parravano MC, Costanzo E, Querques L, Montorio D, et al. Eplerenone versus observation in the treatment of acute central serous chorioretinopathy: a retrospective controlled study. Ophthalmol Ther. 2018;7:109-18.

27. Chin EK, Almeida DR, Roybal CN, Niles PI, Gehrs KM, Sohn $\mathrm{EH}$, et al. Oral mineralocorticoid antagonists for recalcitrant central serous chorioretinopathy. Clin Ophthalmol. 2015;9: 1449-56.

28. Ghadiali Q, Jung JJ, Yu S, Patel SN, Yannuzzi LA. Central serous chorioretinopathy treated with mineralocorticoid antagonists: a one-year pilot study. Retina. 2016;36:611-8.

29. Joshi NP, Adam MK, Samara WA, Shahlaee A, Rahimy E, Aderman CM, et al. Optical density of subretinal fluid as a predictive biomarker for eyes with chronic central serous retinopathy treated with eplerenone. J Vitreoretina Dis. 2018;2:6-11.

30. Leisser C, Hirnschall N, Hackl C, Plasenzotti P, Findl O. Eplerenone in patients with chronic recurring central serous chorioretinopathy. Eur J Ophthalmol. 2016;26:479-84.

31. Pociej-Marciak W, Karska-Basta I, Ozog-Baran J, KubickaTrzaska A, Filemonowicz-Skoczek A, Romanowska-Dixon B. The use of mineralocorticoid receptor antagonists in chronic central serous chorioretinopathy. Klin Ocz. 2016;118: $48-54$.

32. Salz DA, Pitcher JD, Hsu J, Regillo CD, Fineman MS, Elliott $\mathrm{KS}$, et al. Oral eplerenone for treatment of chronic central serous chorioretinopathy: a case series. Ophthalmic Surg, Lasers Imaging Retin. 2015;46:439-44.
33. Sampo M, Soler V, Gascon P, Ho GW, Hoffart L, Denis D, et al. Eplerenone treatment in chronic central serous chorioretinopathy. J Fr d'Ophtalmol. 2016;39:535-42.

34. Singh RP, Sears J, Bedi R, Schachat A, Kaiser PK, Ehlers J. Oral eplerenone for the management of chronic central serous chorioretinopathy. Invest Ophthalmol Vis Sci. 2014;55:1927.

35. Cioboata M, Alexandrescu C, Hopinca CA, Pienaru MC, Merticariu A, Schmitzer S. A new treatment approach-Eplerenone-in central serous chorioretinopathy-case report. J Med Life. 2016;9:92.

36. Gruszka A. Potential involvement of mineralocorticoid receptor activation in the pathogenesis of central serous chorioretinopathy: case report. Eur Rev Med Pharm Sci. 2013;17:1369-73.

37. Willcox A, Culliford L, Ellis L, Rogers CA, Cree A, Chakravarthy $\mathrm{U}$, et al. Clinical efficacy of eplerenone versus placebo for central serous chorioretinopathy: study protocol for the VICI randomised controlled trial. Eye. 2019;33:295.

38. Clinical Trials.Gov-Photodynamic Therapy Versus Eplerenone: Treatment Trial for Chronic Central Serous Chorioretinopathy (SPECT). https://clinicaltrials.gov/ct2/show/NCT03079141. Accessed 26 Apr 2019.

39. Bousquet E, Beydoun T, Rothschild PR, Bergin C, Zhao M, Batista $\mathrm{R}$, et al. Spironolactone for nonresolving central serous chorioretinopathy: a randomized controlled crossover study. Retina. 2015;35:2505-15.

40. Pichi F, Carrai P, Ciardella A, Behar-Cohen F, Nucci P. Comparison of two mineralcorticosteroids receptor antagonists for the treatment of central serous chorioretinopathy. Int Ophthalmol. 2017;37:1115-25.

41. Sun X, Shuai Y, Fang W, Li J, Ge W, Yuan S, et al. Spironolactone versus observation in the treatment of acute central serous chorioretinopathy. Br J Ophthalmol. 2018;102:1060-5.

42. Chai Y, Liu RQ, Yi JL, Ye LH, Zou J, Jiang N, et al. Clinical research of fenofibrate and spironolactone for acute central serous chorioretinopathy. Int J Ophthalmol. 2016;9:1444.

43. Falavarjani KG, Amirsardari A, Habibi A, Eshaghi A, Bakhti S, Aghdam KA. Visual and anatomical outcomes of spironolactone therapy in patients with chronic central serous chorioretinopathy. J Ophthalmic Vis Res. 2017;12:281.

44. Herold TR, Prause K, Wolf A, Mayer WJ, Ulbig MW. Spironolactone in the treatment of central serous chorioretinopathy a case series. Graefes Arch Clin Exp Ophthalmol. 2014;252: 1985-91.

45. Herold TR, Rist K, Priglinger SG, Ulbig MW, Wolf A. Longterm results and recurrence rates after spironolactone treatment in non-resolving central serous chorio-retinopathy (CSCR). Graefes Arch Clin Exp Ophthalmol. 2017;255:221-9.

46. Lee JY, Kim DY, Lee EK, Lee SY, Lee HJ, Jeong JH, et al. Comparison of short-term clinical outcomes between oral spironolactone and observation in acute central serous chorioretinopathy. J Korean Ophthalmol Soc. 2018;59:511-8.

47. Lee JH, Lee SC, Kim H, Lee CS. Comparison of short-term efficacy between oral spironolactone treatment and photodynamic therapy for the treatment of nonresolving central seroud chorioretinopathy. Retina. 2019;39:127-33.

48. Kim JY, Chae JB, Kim J, Kim DY. Mineralocorticoid receptor antagonist treatment for steroid-induced central serous chorioretinopathy patients with continuous systemic steroid treatment. J Ophthalmol. 2018;2018:4258763.

49. Maier M, Stumpfe S, Feucht N, Strobl P, Rath V, Lohmann CP. Mineralocorticoid receptor antagonists as treatment option for acute and chronic central serous chorioretinopathy. Ophthalmologe. 2014;111:173-80.

50. Ángel-Pereira D, Rocha-Cabrera P, Cordovés-Dorta L, Losada Castillo MJ, Blasco Alberto A, Abreu Reyes JA. Spironolactone, 
a therapeutic alternative in the treatment of diffuse retinal pigment epitheliopathy. Arch Soc Esp Oftalmol. 2016;91:599-603.

51. Kapoor KG, Sim J. Spironolactone for secondary central serous chorioretinopathy: a challenge-rechallenge case. Case Rep Ophthalmol. 2017;8:370-4.

52. Ryan EH, Pulido CM. Central serous chorioretinopathy treatment with spironolactone: a challenge-rechallenge case. Retin Cases Brief Rep. 2015;9:235-8.

53. Craft J. Eplerenone (Inspra), a new aldosterone antagonist for the treatment of systemic hypertension and heart failure. Bayl Univ Med Cent Proc. 2004;17:217-20.

54. Lainscak M, Pelliccia F, Rosano G, Vitale C, Schiariti M, Greco C, et al. Safety profile of mineralocorticoid receptor antagonists: spironolactone and eplerenone. Int J Cardiol. 2015;200:25-9.

55. Avci R, Deutman AF. Treatment of central serous choroidopathy with the beta receptor blocker metoprolol (preliminary results). Klin Monbl Augenheilkd. 1993;202:199-205.

56. Chatziralli I, Kabanarou SA, Parikakis E, Chatzirallis A, Xirou T, Mitropoulos P. Risk factors for central serous chorioretinopathy: multivariate approach in a case-control study. Curr Eye Res. 2017;17:1-5.

57. Chrapek O, Jirkova B, Kandrnal V, Rehak J, Sin M. Treatment of central serous chorioretinopathy with beta-blocker metipranolol. Biomed Pap Med Fac Univ Palacky Olomouc Czech Repub. 2015;159:3-6.

58. Browning DJ. Nadolol in the treatment of central serous retinopathy. Am J Ophthalmol. 1993;116:770-1.

59. Kianersi F, Fesharaki F. Effects of propranolol in patients with central serous chorioretinopathy. J Res Med Sci. 2008;13:103-7.

60. Tatham A, Macfarlane A. The use of propranolol to treat central serous chorioretinopathy: an evaluation by serial OCT. J Ocul Pharmacol Ther. 2006;22:145-9.

61. Fabianova J, Porubska M, Cepilova Z. Central serous chorioretinopathy-treatment with beta blockers. Ceska a Slov Oftalmol: Cas Ceske Oftalmol Spol a Slov Oftalmol Spol. 1998;54:401-4.

62. D'Elios MM, Andersen LP. Helicobacter pylori: inflammation, immunity, and vaccines. Helicobacter. 2007;12(Suppl 1):15-9.

63. Bohr URM, Annibale B, Franceschi F, Roccarina D, Gasbarrini A. Extragastric manifestations of Helicobacter pylori infectionother Helicobacters. Helicobacter. 2007;12(Suppl 1):45-53.

64. Feghhi M, Hajiani E, Khataminia GH. Incidence of Helicobacter pylori in central serous chorioretinopathy: a case control study. Jundishapur J Microbiol. 2008;1:15-19.

65. Mitchell HM. The epidemiology of Helicobacter pylori. Curr Top Microbiol Immunol. 1999;241:11-30.

66. Giusti C. Central serous chorioretinopathy: a new extragastric manifestation of Helicobacter pylori? Analysis of a clinical case. Clin Ter. 2001;152:393-7.

67. Mauget-Faÿsse M, Kodjikian L, Quaranta M, Ben Ezra D, Trepsat C, Mion F, et al. Rôle de l'Helicobacter pylori dans la choriorétinopathie séreuse centrale et l'épithéliopathie rétinienne diffuse. Résultats de la première étude prospective pilote. J Fr Ophtalmol. 2002;25:1021-5.

68. Asensio-Sánchez VM, Rodríguez-Delgado B, García-Herrero E, Cabo-Vaquera V, García-Loygorri C. Coriorretinopatía serosa central como manifestación extradigestiva de infección gástrica por Helicobacter pylori. Arch Soc Esp Oftalmol. 2008;83: 177-82.

69. Ahnoux-Zabsonre A, Quaranta M, Mauget-Faÿsse M. Prevalence of Helicobacter pylori in central serous chorioretinopathy and diffuse retinal epitheliopathy: a complementary study. J Fr Ophtalmol. 2004;27:1129-33.

70. Giusti C. Association of Helicobacter pylori with central serous chorioretinopathy: hypotheses regarding pathogenesis. Med Hypotheses. 2004;63:524-7.
71. Borrelli M, D'Alessio AC, Menzione M, Villani A, Piccolo G, Montella F, et al. Central serous chorioretinopathy and Helicobacter pylori. Eur J Ophthalmol. 2006;16:274-8.

72. Misiuk-Hojło M, Michałowska M, Turno-Krecicka A. Helicobacter pylori-a risk factor for the development of the central serous chorioretinopathy. Klin Ocz. 2009;111:30-2.

73. Roshani M, Davoodi NA, Seyyedmajidi MR, et al. Association of Helicobacter pylori with central serous chorioretinopathy in Iranian patients. Gastroenterol Hepatol Bed Bench. 2014;7: 63-67.

74. Maeda S, Mentis AF. Pathogenesis of Helicobacter pylori infection. Helicobacter. 2007;12((Suppl 1):10-4.

75. Whittle BJR, Morschl E, Pozsár J, Moran AP, László F. Helicobacter pylori lipopolysaccharide provokes iNOS-mediated acute systemic microvascular inflammatory responses in rat cardiac, hepatic, renal and pulmonary tissues. J Physiol Paris. 2001;95:257-9.

76. Giusti C, Mauget-Faÿsse M. Helicobacter pylori and idiopathic central serous chorioretinopathy. Swiss Med Wkly. 2004;134: 395-8.

77. Casella AMB, Berbel RF, Bressanim GL, Malaguido MR, Cardillo JA. Helicobacter pylori as a potential target for the treatment of central serous chorioretinopathy. Clinics. 2012;67: 1047-52.

78. Rahbani-Nobar MB, Javadzadeh A, Ghojazadeh L, Rafeey M, Ghorbanihaghjo A. The effect of Helicobacter pylori treatment on remission of idiopathic central serous chorioretinopathy. Mol Vis. 2011;17:99-103.

79. Dang Y, Mu Y, Zhao M, Li L, Guo Y, Zhu Y. The effect of eradicating Helicobacter pylori on idiopathic central serous chorioretinopathy patients. Ther Clin Risk Manag. 2013;9: $355-60$.

80. Zavoloka O, Bezditko P, Lahorzhevska I, Zubkova D, Ilyina Y. Clinical efficiency of Helicobacter pylori eradication in the treatment of patients with acute central serous chorioretinopathy. Graefe's Arch Clin Exp Ophthalmol. 2016;254:1737-42.

81. Masayoshi S, Nozomi F, Yutaka K. Rifampicin as an oral angiogenesis inhibitor targeting hepatic cancers. Cancer Res. 2009;69:4760-8.

82. UpToDate. Rifampin. http://www.uptodate.com/contents/rifampinrifampicin-drug-information?source $=$ search_result\&selectedTitle $=$ 1\%7E150. Accessed 30 Nov 2016.

83. Guengerich FP. Cytochrome P-450 3A4: regulation and role in drug metabolism. Annu Rev Pharm Toxicol. 1999;39:1-17.

84. Pikuleva IA. Cytochrome P450s and cholesterol homeostasis. Pharm Ther. 2006;112:761-73.

85. Epocrates. Rifampicin. https://online.epocrates.com/noFrame/ showPage.do?method=analyze \&MonographId=280\&MultiBra ndAlert $=$ false. Accessed 3 Oct 2016.

86. PDR.net. Rifampicin. 2011. http://www.pdr.net/drugpages/ concisemonograph.aspx? concise $=564$. Accessed 3 Oct 2016.

87. Ravage Z, Packo K. Rifampin for treatment of central serous chorioretinopathy. Invest Ophthalmol Vis Sci. 2011;52:2137.

88. Ravage ZB, Packo KH, Creticos CM, Merrill PT. Chronic central serous chorioretinopathy responsive to rifampin. Retin Cases Brief Rep. 2012;6:129-32.

89. Steinle NC, Gupta N, Yuan A, Singh RP. Oral rifampin utilisation for the treatment of chronic multifocal central serous retinopathy. Br J Ophthalmol. 2012;96:10-3.

90. Pouw AE, Olmos de Koo LC. Oral rifampin for central serous retinopathy: a strategic approach in three patients. Ophthalmic Surg Lasers Imaging Retin. 2015;46:98-102.

91. Shulman S, Goldenberg D, Schwartz R, Habot-Wilner Z, Barak A, Ehrlich N, et al. Oral Rifampin treatment for longstanding chronic central serous chorioretinopathy. Graefes Arch Clin Exp Ophthalmol. 2016;254:15-22. 
92. Mårde Arrhén Y, Nylén H, Lövgren-Sandblom A, Kanebratt KP, Wide K, Diczfalusy U. A comparison of $4 \beta$-hydroxycholesterol : cholesterol and 6 $\beta$-hydroxycortisol: cortisol as markers of CYP3A4 induction. Br J Clin Pharm. 2013;75:1536-40.

93. Khan MS, Sameen M, Lodhi AA, Ahmed M, Ahmed N, Kamal $\mathrm{M}$, et al. Effect of half adult dose of oral Rifampicin (300mg) in patients with idiopathic central serous chorioretinopathy. Pak J Med Sci. 2016;32:1158.

94. Venkatesh R, Agarwal M, Kantha M. Efficacy of oral rifampicin in chronic central serous chorioretinopathy. Ther Adv Ophthalmol. 2018;10:2515841418807130.

95. Nelson J, Saggau DD, Nielsen JS. Rifampin induced hepatotoxicity during treatment for chronic central serous chorioretinopathy. Retin Cases Brief Rep. 2014;8:70-2.

96. Cronstein BN. Low-dose methotrexate: a mainstay in the treatment of rheumatoid arthritis. Pharm Rev. 2005;57:163-72.

97. Kerbel RS, Kamen BA. The anti-angiogenic basis of metronomic chemotherapy. Nat Rev Cancer. 2004;4:423-36.

98. Munoz R, Shaked Y, Bertolini F, Emmenegger U, Man S, Kerbel RS. Anti-angiogenic treatment of breast cancer using metronomic low-dose chemotherapy. Breast. 2005;14:466-79.

99. Baggott JE, Morgan SL, Vaughn WH. Differences in methotrexate and 7-hydroxymethotrexate inhibition of folate dependent enzymes of purine nucleotide biosynthesis. Biochem J. 1994;300:627-9.

100. Kurup SK, Oliver A, Emanuelli A, Hau V, Callanan D. Lowdose methotrexate for the treatment of chronic central serous chorioretinopathy: a retrospective analysis. Retina. 2012;32: 2096-101.

101. Abrishami M, Mousavi M, Hosseini SM, Norouzpour A. Treatment of chronic central serous chorioretinopathy with oral methotrexate. J Ocul Pharm Ther. 2015;31:468-75.

102. Yamada R, Yamada S, Ishii A, Tane S. Evaluation of tissue plasminogen activator and plasminogen activator inhibitor-1 in blood obtained from patients of idiopathic central serous chorioretinopathy. Nippon Ganka Gakkai Zasshi. 1993;97:955-60.

103. Iijima $\mathrm{H}$, Iida $\mathrm{T}$, Murayama $\mathrm{K}$, Imai $\mathrm{M}$, Gohdo T. Plasminogen activator inhibitor 1 in central serous chorioretinopathy. Am J Ophthalmol. 1999;127:477-8.

104. Caccavale A, Romanazzi F, Imparato M, Negri A, Morano A, Ferentini F. Central serous chorioretinopathy: a pathogenetic model. Clin Ophthalmol. 2011;5:239-43.

105. Pecora JL. Ibuprofen in the treatment of central serous chorioretinopathy. Ann Ophthalmol. 1978;10:1481-3.

106. Caccavale A, Imparato M, Romanazzi F, Negri A, Porta A, Ferentini F. A new strategy of treatment with low-dosage acetyl salicylic acid in patients affected by central serous chorioretinopathy. Med Hypotheses. 2009;73:435-7.

107. Caccavale A, Romanazzi F, Imparato M, Negri A, Morano A, Ferentini F. Low-dose aspirin as treatment for central serous chorioretinopathy. Clin Ophthalmol. 2010;4:899-903.

108. Sibilia J, Ravaud P, Marck G. Digestive and hemorrhage complications of low-dose aspirin. Presse Med. 2003;32(37 Pt 2): S17-S28.

109. Cox SN, Hay E, Bird AC. Treatment of chronic macular edema with acetazolamide. Arch Ophthalmol. 1988;106:1190-5.

110. Tripathi RC, Fekrat S, Tripathi BJ, Ernest JT. A direct correlation of the resolution of pseudophakic cystoid macular edema with acetazolamide therapy. Ann Ophthalmol. 1991;23:127-9.

111. Wolfensberger TJ, Dmitriev AV, Govardovskii VI. Inhibition of membrane-bound carbonic anhydrase decreases subretinal $\mathrm{pH}$ and volume. Doc Ophthalmol. 1999;97:261-71.

112. Wolfensberger TJ. The role of carbonic anhydrase inhibitors in the management of macular edema. Doc Ophthalmol. 1999;97: 387-97.
113. Wolfensberger TJ, Chiang RK, Takeuchi A, Marmor MF. Inhibition of membrane-bound carbonic anhydrase enhances subretinal fluid absorption and retinal adhesiveness. Graefes Arch Clin Exp Ophthalmol. 2000;238:76-80.

114. Steinsapir KD, Tripathi RC, Tripathi BJ, Ernest JT. Inhibition of ocular gamma glutamyl transpeptidase by acetazolamide [letter]. Exp Eye Res. 1992;55:179-81.

115. Geyer DR, Gragoudas ES. Central serous chorioretinopathy. In: Albert DM, Jakobiec FA, editors. Principles and practice of ophthalmology. Philadelphia, USA: WB Saunders; 1994. p. 818-25.

116. Pomykala M, Rubin P, Rubin JS. Recurrent central serous chorioretinopathy associated with retinitis pigmentosa treated with carbonic anhydrase inhibitors. Retin Cases Brief Rep. 2016;10:205-7.

117. Das D, Nigam E. Resolution of cystoid macular edema by topical dorzolamide in a case of central serous chorioretinopathy: a case report. Sci J Med \& Vis Res Foun. 2017;35.

118. Pikkel J, Beiran I, Ophir A, Miller B. Acetazolamide for central serous retinopathy. Ophthalmology. 2002;109:1723-5.

119. Jung-Testas I, Baulieu EE. Inhibition of glucocorticosteroid action in cultured L-929 mouse fibroblasts by RU 486, a new anti-glucocorticosteroid of high affinity for the glucocorticosteroid receptor. Exp Cell Res. 1983;147:177-82.

120. Shoupe D, Mishell DR Jr, Brenner PF, Spitz IM. Pregnancy termination with a high and medium dosage regimen of RU 486. Contraception. 1986;33:455-61.

121. Nielsen JS, Weinreb RN, Yannuzzi L, Jampol LM. Mifepristone treatment of chronic central serous chorioretinopathy. Retina. 2007;27:119-22.

122. Nielsen JS, Bachhawat A, Jampol LM. A case of chronic severe central serous chorioretinopathy responding to oral mifepristone: update. Retina. 2008;28:1363.

123. Nielsen JS, Jampol LM. Oral mifepristone for chronic central serous chorioretinopathy. Retina. 2011;31:1928-36.

124. Goldberg RA, Heier JS. Short-term oral mifepristone for the treatment of central serous chorioretinopathy (STOMP CSC) - a randomized, placebo-controlled study. Invest Ophthalmol Vis Sci. 2018;59:782-782.

125. Pandi-Perumal SR, Trakht I, Spence DW, Srinivasan V, Dagan Y, Cardinali DP. The roles of melatonin and light in the pathophysiology and treatment of circadian rhythm sleep disorders. Nat Clin Pr Neurol. 2008;4:436-47.

126. Hardeland R, Pandi-Perumal SR, Cardinali DP. Melatonin. Int J Biochem Cell Biol. 2006;38:313-6.

127. Gramajo AL, Marquez GE, Torres VE, Juárez CP, Rosenstein RE, Luna JD. Therapeutic benefit of melatonin in refractory central serous chorioretinopathy. Eye (Lond). 2015;29:1036-45.

128. Townsend KA, Marlowe KF. Relative safety and efficacy of finasteride for treatment of hirsutism. Ann Pharm. 2004;38:1070-3.

129. Goetzl MA, Holzbeierlein JM. Finasteride as a chemopreventive agent in prostate cancer: impact of the PCPT on urologic practice. Nat Clin Pr Urol. 2006;3:422-9.

130. Kaufman KD, Rotonda J, Shah AK, et al. Long-term treatment with finasteride $1 \mathrm{mg}$ decreases the likelihood of developing further visible hair loss in men with androgenetic alopecia (male pattern hair loss). Eur J Dermatol. 2008;18:400-6.

131. Forooghian F, Meleth AD, Cukras C, Chew EY, Wong WT, Meyerle CB. Finasteride for chronic central serous chorioretinopathy. Retina. 2011;31:766-71.

132. Moisseiev E, Holmes AJ, Moshiri A, Morse LS. Finasteride is effective for the treatment of central serous chorioretinopathy. Eye (Lond). 2016;30:850-6.

133. Chou SC, Lin JD. Longterm effects of ketoconazole in the treatment of residual or recurrent Cushing's disease. Endocr J. 2000;47:401-6. 
134. Winquist EW, Laskey J, Crump M, Khamsi F, Shepherd FA. Ketoconazole in the management of paraneoplastic Cushing's syndrome secondary to ectopic adrenocorticotropin production. J Clin Oncol. 1995;13:157-64.

135. Meyerle CB, Freund KB, Bhatnagar P, Shah V, Yannuzzi LA. Ketoconazole in the treatment of chronic idiopathic central serous chorioretinopathy. Retina. 2007;27:943-6.

136. Golshahi A, Klingmüller D, Holz FG, Eter N. Ketoconazole in the treatment of central serous chorioretinopathy: a pilot study. Acta Ophthalmol. 2010;88:576-81.
137. Ratanasukon M, Bhurayanontachai $P$, Jirarattanasopa $P$. High-dose antioxidants for central serous chorioretinopathy; the randomized placebo-controlled study. BMC Ophthalmol. 2012;12:20.

138. Mazzolani F. Pilot study of oral administration of a curcuminphospholipid formulation for treatment of central serous chorioretinopathy. Clin Ophthalmol. 2012;6:801-6.

139. Mazzolani F, Togni S. Oral administration of a curcuminphospholipid delivery system for the treatment of central serous chorioretinopathy: a 12-month follow-up study. Clin Ophthalmol. 2013;7:939-45. 